\title{
Institution Based Prospective Cross-Sectional Study on Patterns of Neonatal Morbidity at Gondar University Hospital Neonatal Unit, North-West Ethiopia
}

\author{
Mehretie Kokeb ${ }^{1}$, Teshome Desta ${ }^{2}$
}

\begin{abstract}
BACKGROUND: Every year, millions of babies are born and a large proportion of them are being admitted to hospital for various indications. This study was conducted to identify the general characteristics, disease spectrum and common causes of Neonatal morbidity and mortality at Gondar University Hospital, Neonatal Unit.

METHODS: Institution based prospective cross-sectional study was conducted at Gondar University Hospital (GUH), Neonatal Unit, from January $1^{\text {st }}$ to March 31 ${ }^{\text {st }}$, 2014. The study included 325 newborns who were admitted to the unit during the study period. The neonates were followed up using structured checklist and neonatal parameters like Neonatal sex, place of delivery, address, length of stay, gestational age, diagnosis and discharge conditions were transcribed into an electronic database for all observations. The primary outcome measures were death and cause of death.

RESULTS: A total of 325 neonates were admitted during the study period. Of these, $75.1 \%, 23.1 \%, 1.2 \%$ and $0.6 \%$ were discharged improved, died, discharged with same condition and disappeared, respectively. Ten variables were found to have significant statistical associations with neonatal mortality after adjusting for demographic covariates: Prematurity $(p<0.001)$, Meningitis $(p<0.001)$, Hemorrhagic Diseases (P <0.001), Hyaline Membrane Disease $(P<0.001)$, Neonatal Sepsis $(p<0.05)$, Meningitis $(<0.05)$, Perinatal Asphyxia $(p<0.05)$, Neonatal Seizure $(p<0.05)$, Home delivery $(p<0.05)$ and Meconium Aspiration $(p<0.05)$.

CONCLUSION: Our study showed that the common causes of neonatal mortality are almost similar with the previous evidences (problems of prematurity, Asphyxia and Sepsis).

KEYWORDS: Neonatal, Morbidity, Mortality, Gondar
\end{abstract}

DOI: http://dx.doi.org/10.4314/ejhs.v26i1.12

\section{INTRODUCTION}

About 7 million children died before their $5^{\text {th }}$ birthday in the year 2011 worldwide. From these, about 5 million died before the age of one and nearly 3 million died within the first 28 days of birth. This evidence showed that $43 \%$ of underfive deaths and $60 \%$ of infant deaths were contributed by the neonatal mortality globally (1). This report pointed out that it is difficult to achieve the desired target for the reduction of infant and under- five mortality without particular focus on neonatal mortality. More than $98 \%$ of these neonatal deaths occurred in low and middle income countries. Sub-Saharan Africa is the region of the world with the highest level of child and neonatal morbidity and mortality. In this region, 1 in 9 children dies before the age of five, which is more than 16 times of the average for the developed regions (1 in 152). Similarly, this region has the highest risk of death in the first month of life, and is among the regions showng the least progress (3). The 2011 Ethiopian Demog-

\footnotetext{
${ }^{1}$ Department of Pediatrics and Child Health, University of Gondar, Ethiopia

${ }^{2}$ WHO Regional Office ,IST/ESA,Harare,Zimbabwe

Corresponding Author: Mehretie Kokeb, Email: mehretiek@gmail.co
} 
raphic and Health Survey (EDHS) showed a rapid decrease in infant and under-five mortality compared to the 2005 EDHS. During this period, under-five mortality decreased by $28 \%$ (from 123 to 88 ). Infant mortality decreased by $23 \%$ (from 77 to 59) but the neonatal mortality showed reduction only by $5 \%$ (from 39 to 37 ) from 2005 to 2011 .

\section{MATERIALS AND METHODS}

Hand-written patient records, completed routinely by interns and residents, were transcribed by a senior resident into an electronic database. All admissions during the three months period (from January $1^{\text {st }}$ to March 31 st, 2014) were included in the study. Neonates who died on arrival with no documented diagnoses were excluded. Data unavailable in the patient records in the ward were retrieved through review of patient charts and discharge certificates from the record office.

All discharge outcomes were transcribed as 'Discharged improved', 'Died', and 'Discharged with same condition 'or 'Disappeared". The primary outcome measures were death and cause of death.

For each neonate,identification number, place of delivery, mode of delivery, maternal antenatal care, maternal education andparent income were transcribed.In addition, age at admission, sex, address, identified problems, investigation results, interventions made, dates of admission and discharge, diagnosis and discharge conditions of neonates were transcribed.

Geographical data were dichotomized according to Ethiopian administrative maps, so that all patient origins could be recognized as either within or outside Gondar. Associations between each variable and primary outcome measures were determined by univariate logistic regression analysis. Odds ratio (OR) was calculated for each diagnosis using multiple logistic regressions. Significance was defined as P $\leq 0.05$. Both descriptive and comparative statistics were generated with SPSS version 16.0.

Ethical approval for this study was secured from Internal Review Board at the University of Gondar, College of Medicine and Health Sciences.
Permission letter for conducting the research was obtained from Gondar University Hospital.

\section{RESULTS}

A total of 325 neonates were included in the study. Of these, $179(55.1 \%)$ were from Gondar; $158(48.6 \%)$ were females and 257(79.1\%) were delivered in the same hospital. The mean maternal age was found to be 25.6 years with standard deviation of 4.3 years, while the minimum maternal age was 17 years. Two hundred eightyfive $(87.7 \%)$ of the mothers had had at least one antenatal followup; $83.7 \%$ of the babies were delivered as singleton, $13.2 \%$ as twin and $3.1 \%$ as triplet. One hundred ninety-two (59.1\%), $80(24.6 \%), 50(15.4 \%)$ and $3(0.9 \%)$ deliveries were effected by Spontaneous Vaginal Delivery, Cesarean Section, Instrumental Delivery and Breach Extractions, respectively. Only 33(10.1\%) deliveries were home deliveries. Preterm delivery was reported in $89(27.4 \% \%)$ neonates. Eightyeight $(27.1 \%)$ and $29(8.9 \%)$ newborns were delivered with low birth weight and very low birth weight, respectively (Table 1). Final outcome of newborns was reported as improved, died, discharged with same condition and disappeared in $75.1 \%, 23.1 \%, 1.2 \%$ and $0.6 \%$ of newborns, respectively (Figure1).

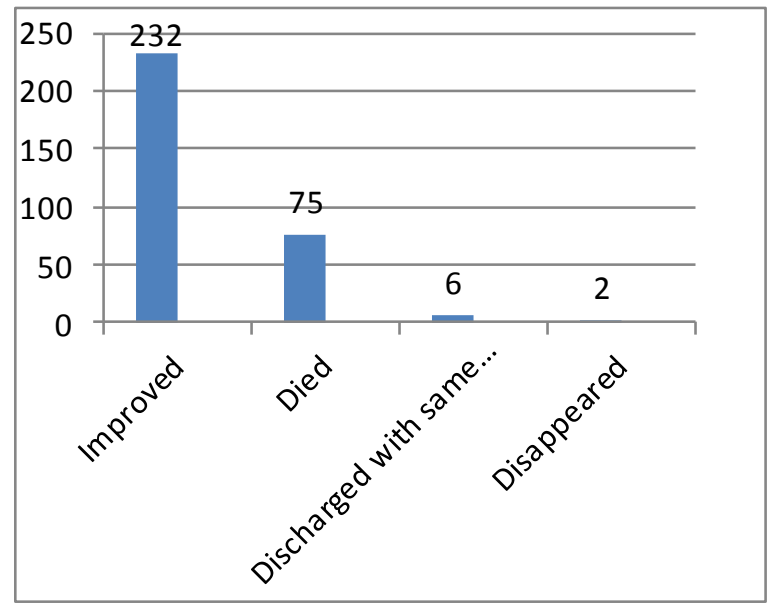

Figure 1: Final outcome of newborns 
Patterns of Neonatal Morbidity...

Mehretie K. et al

Table 1: Neonatal Outcome versus socio-demographic and other clinical parameters

\begin{tabular}{|c|c|c|c|}
\hline \multirow{2}{*}{\multicolumn{2}{|c|}{ Characteristics }} & \multicolumn{2}{|c|}{ Final outcome ${ }^{*}$} \\
\hline & & \multirow{2}{*}{$\begin{array}{l}\text { Improved } \\
133(54.9 \%)\end{array}$} & \multirow{2}{*}{$\begin{array}{l}\text { Died } \\
42(56.0 \%)\end{array}$} \\
\hline \multirow[b]{2}{*}{ Address } & Gondar & & \\
\hline & Out of Gondar & $109(45.1 \%)$ & $33(44.0 \%)$ \\
\hline \multirow[b]{2}{*}{ Place of Delivery } & Inborn & $189(78.1 \%)$ & $63(84.0 \%)$ \\
\hline & Out Born & $53(21.9 \%)$ & $12(16.0 \%)$ \\
\hline \multirow{2}{*}{ ( } & Female & $114(47.1 \%)$ & $41(54.7 \%)$ \\
\hline & Male & $128(52.9 \%)$ & $34(45.3 \%)$ \\
\hline \multirow[b]{2}{*}{ ANC (at least once) } & Yes & $21488.4 \%)$ & $67(89.3 \%)$ \\
\hline & No & $28(11.6 \%)$ & $8(10.7 \%)$ \\
\hline \multirow{3}{*}{$\begin{array}{ll}\begin{array}{l}\text { Number } \\
\text { delivered }\end{array} & \text { of } \text { Babies } \\
\end{array}$} & Singleton & $217(89.7 \%)$ & $51(68 \%)$ \\
\hline & Twin & $22(9.1 \%)$ & $18(24 \%)$ \\
\hline & Triplet & $3(1.2 \%)$ & $6(8 \%)$ \\
\hline \multirow[b]{2}{*}{ Maternal Disease } & Yes & $27(11.2 \%)$ & $13(17.3 \%)$ \\
\hline & No & $215(88.8 \%)$ & $62(82.7 \%)$ \\
\hline \multirow{4}{*}{ Monthly Income } & $<500$ & $6(2.5 \%)$ & $2(2.7 \%)$ \\
\hline & $500-1000$ & $93(38.4 \%)$ & $27(36.0 \%)$ \\
\hline & $1000-1500$ & $76(31.4 \%)$ & $25(33.3 \%)$ \\
\hline & $>=1500$ & $67(27.7 \%)$ & $21(28.0 \%)$ \\
\hline \multirow[t]{2}{*}{ Marital status } & married & $234(96.7 \%)$ & $75(100.0 \%)$ \\
\hline & single mother & $8(3.3 \%)$ & $0(.0 \%)$ \\
\hline \multirow{4}{*}{ GA by date (weeks) } & $28-34$ & $22(9.6 \%)$ & $26(34.7 \%)$ \\
\hline & $34-37$ & $27(11.2 \%)$ & $10(13.3 \%)$ \\
\hline & $37-42$ & $186(76.9 \%$ & $36(48.0 \%)$ \\
\hline & $>=42$ & $1(0.4 \%)$ & $3(4.0 \%)$ \\
\hline \multirow{4}{*}{ Place of Delivery } & Home & $26(10.7 \%)$ & $6(8 \%)$ \\
\hline & Hc/Clinic & $26(10.7 \%)$ & $5(6.7 \%)$ \\
\hline & Hospital & $188(77.7 \%)$ & $64(85.3 \%)$ \\
\hline & on the way & $2(0.9 \%)$ & $0(.0 \%)$ \\
\hline \multirow{5}{*}{ Mode of delivery } & SVD & $148(61.2 \%)$ & $40(53.4 \%)$ \\
\hline & Forceps & $15(6.2 \%)$ & $13(17.3 \%)$ \\
\hline & Vaccum & $16(6.6 \%)$ & $3(4 \%)$ \\
\hline & $\mathrm{C} / \mathrm{S}$ & $61(25.2 \%)$ & $18(24 \%)$ \\
\hline & Breech extraction & $2(0.8 \%)$ & $1(1.3 \%)$ \\
\hline \multirow{4}{*}{ Maternal Education } & Illitrate & $47(19.4 \%)$ & $9(12.0 \%)$ \\
\hline & Read and write & $57(21.5 \%)$ & $38(50.7 \%)$ \\
\hline & Elementary & $81(33.5 \%)$ & $21(28.0 \%)$ \\
\hline & Secondary & $35(14.6 \%)$ & $7(9.3 \%)$ \\
\hline \multirow{4}{*}{ Birth weight (gm) } & $<1500$ & $8(3.3 \%)$ & $19(25.3 \%)$ \\
\hline & $1500-2500$ & $68(28.1 \%)$ & $18(24.0 \%)$ \\
\hline & $2500-4000$ & $160(66.1 \%)$ & $38(50.7 \%)$ \\
\hline & $>=4000$ & $6(2.5 \%)$ & $0(0 \%)$ \\
\hline
\end{tabular}

"Six newborns were discharged with same condition and 2 newborns disappeared with unknown outcome

Thirty-six percent of neonatal deaths were found to happen before 24 hours of neonatal age. The average hospital stay was 6.42 days. Antibiotics were given to $89.2 \%$ of the babies, the most frequently administered one being a combination of Ampicillin and Gentamycin (90\%). Other 
combinations were found to be Cloxacillin with Gentamycin (3\%) and Ceftriaxone with Gentamayicin (2.5\%). Oxygen was administered to $178(54.8 \%)$ newborns.

Direct blood transfusion, partial exchange transfusion, Double exchange transfusion and phototherapy were applied in 9.5\%, 3.1\%, 4.6\% and $23.7 \%$ of newborns, respectively.

Among neonatal problems at admission, Neonatal Sepsis (77.8\%), Hypothermia (57.5\%), Low birth weight $(32.9 \%)$, Jaundice $(31.7 \%)$, Hypoglycemia (31.7\%), Prematurity (27.4\%),
Hyaline Membrane Disease (19.7\%), Meconium Aspiration Syndrome (18.8\%) and Perinatal Asphyxia $(16.6 \%)$ were found to be more frequent.

Case fatality was found to be significantly high in a newborn with diagnoses of Neonatal Tetanus (100\%), Intracranial Hemorrhage (100\%), Very Low Birth Weight $(60 \%)$, Hyaline Membrane Disease $(53.1 \%)$, Neonatal Seizure (50\%), Perinatal Asphyxia (48.1\%), Necrotizing Enterocolitis $(46.2 \%)$, Prematurity $(40.4 \%)$ and Meningitis (37.5\%) (Table 2).

Table 2: Case frequency and fatality rates among neonates admitted to Gondar University Hospital, Neonatal Unit, January $1^{\text {st }}$-March 31 st, and 2014, by diagnosis $(n=325)$

\begin{tabular}{|l|l|l|}
\hline Diagnosis & Frequency (\%) & Case Fatality (\%) \\
\hline Prematurity & $89(27.4 \%)$ & $36(40.4 \%)$ \\
\hline Neonatal sepsis & $253(77.8 \%)$ & $68(26.9 \%)$ \\
\hline Hypothermia & $187(57.5 \%)$ & $59(31.6 \%)$ \\
\hline VLBW & $30(9.2 \%)$ & $18(60 \%)$ \\
\hline LBW & $77(23.7 \%)$ & $18(23.4 \%)$ \\
\hline SGA & $41(12.6 \%)$ & $7(17.1 \%)$ \\
\hline Hypoglycemia & $103(31.7 \%)$ & $27(27.2 \%)$ \\
\hline PNA & $54(16.6 \%)$ & $26(48.1 \%)$ \\
\hline Meningitis & $24(7.4 \%)$ & $9(37.5 \%)$ \\
\hline Neonatal Seizure & $42(12.9 \%)$ & $21(50.0 \%)$ \\
\hline Hyaline Membrane Disease & $64(19.7 \%)$ & $34(53.1 \%)$ \\
\hline Meconium Aspiration & $6(18.8 \%)$ & $21(34.4 \%)$ \\
\hline Polycythemia & $12(3.7 \%)$ & $1(8.3 \%)$ \\
\hline Anemia & $28(8.6 \%)$ & $4(14.3 \%)$ \\
\hline Cephalohematoma & $20(6.2 \%)$ & $6(30.0 \%)$ \\
\hline Subgaleal Hematoma & $24(7.4 \%)$ & $8(33.3 \%)$ \\
\hline Jaundice & $103(31.7 \%)$ & $33(32.0 \%)$ \\
\hline Shock & $12(3.7 \%)$ & $4(33.3 \%)$ \\
\hline Intracranial Hemorrhage & $7(2.2 \%)$ & $7(100 \%)$ \\
\hline Necrotizing Enterocolitis & $13(4.0 \%)$ & $6(46.2 \%)$ \\
\hline Neonatal Tetanus & $2(0.6 \%)$ & $2(100 \%)$ \\
\hline Hemorrhagic Disease & $32(9.8 \%)$ & $8(25 \%)$ \\
\hline Uvulectomy & $46(14.2 \%)$ & $5(10.9 \%)$ \\
\hline & &
\end{tabular}

Ten variables were found to have significant statistical association with neonatal mortality after adjusting for demographic covariates. Four variables:Prematurity $(\mathrm{p}<0.001)$, Meningitis ( $\mathrm{p}$ $<0.001)$, Hemorrhagic Diseases $(\mathrm{P}<0.001)$, and Hyaline Membrane Disease $(\mathrm{P}<0.001)$ were having strong association $(\mathrm{P}<0.001)$ The other 6 variables: Neonatal Sepsis ( $p<0.05)$, Perinatal Asphyxia $(p<0.05)$, Neonatal Seizure $(p<0.05)$, Home delivery $(\mathrm{p}<0.05)$ and Meconium Aspiration $(\mathrm{p}<0.05)$ were also found to have significant statistical association (Table 3 ). 
Table 3: Relating conditions to death among Neonatal admissions to Gondar University Hospital, Neonatal Unit from January $1^{\text {st }}$-March 31st, and 2014

\begin{tabular}{|lllll|}
\hline & & Adjusted & $95.0 \%$ CI \\
Characteristics & P-value & Odds ratio & Lower & Upper \\
\hline Address & .802 & 1.092 & .548 & 2.176 \\
Maternal Education & .160 & 1.250 & .916 & 1.707 \\
Preterm & .001 & .074 & .016 & .338 \\
Low Birth weight & .022 & 4.215 & 1.230 & 14.451 \\
Hypothermia & .512 & 1.444 & .482 & 4.326 \\
Hypoglycemia & .494 & 1.299 & .614 & 2.745 \\
Perinatal Asphyxia & .011 & .218 & .068 & .702 \\
Neonatal Sepsis & .045 & 3.44 & 1.005 & 11.5 \\
Meningitis & .004 & .126 & .031 & .507 \\
Seizure & .030 & .305 & .104 & .892 \\
Hyaline & & & & \\
disease & .000 & 3.102 & 1.241 & 1.270 \\
Meconium Aspiration & .005 & .211 & .072 & .620 \\
Congenital Anomaly & .002 & .073 & .014 & .391 \\
Hemorrhagic Disease & .000 & .056 & .015 & .205 \\
Home Delivery & .018 & .286 & .102 & .807 \\
\hline
\end{tabular}

\section{DISCUSSION}

This prospective cross-sectional study was designed to evaluate a 3 months' pattern of neonatal admissions at the Neonatal Unit of GUH. Neonatal mortality was found to be $23.1 \%$ in the unit, which is significantly higher than the national neonatal mortality rate of 37 (EDHS 2011). This may be explained by the fact that the study was done in a tertiary referral unit where most critically sick babies are being admitted. The current mortality is significantly lower than a research done in the same unit before 9 years, which showed mortality rate of $44.1 \%$. This shows that there is progressive reduction in neonatal death in the unit but still not a fast drop in the last 9 years (2). Overall,; there is $40 \%$ reduction in under-five mortality in Ethiopia in the last 15 years, but still neonatal and post neonatal mortality rates did not show significant reduction $(3,4)$. Common contributing factors of neonatal death in this study were Prematurity, Home delivery, Meningitis, Hemorrhagic Diseases, Neonatal Sepsis, Perinatal Asphyxia, Neonatal Seizure and Meconium Aspiration. Three causes
(Infection, Preterm complications and Asphyxia) are still found to be major causes of Neonatal death in Africa, which was also reflected in this study showing that most deaths are related, directly or as a contributing factor, to prematurity, Infection and Asphyxia (1). Maternal education, birth interval and antenatal care were found to have significant effects on neonatal mortality in different studies done in Ethiopia and other countries, which is not the case in this study $(5,6$, 7). This difference may be explained by the fact that this study was done in a referral hospital where $87.7 \%$ of mothers had at least one visit of antenatal care and $87 \%$ of the deliveries happened in health institution. Common causes of deaths identified in the study were almost similar with an analysis done in Swaziland (8).

In many developing countries, major causes of fatality were found to be infections, Tetanus , Prematurity and Asphyxia, which is consistent with this study, revealing high case fatality rate in newborns with Tetanus, Asphyxia and problems related with prematurity like very low birth weight and intracranial hemorrhage $(9,10)$. A study done in a Nigerian tertiary hospital, NICU, overall 
neonatal mortality rate was found to be $16.0 \%$, which is lower than the result of this study. In the same study, major causes of deaths were Asphyxia, preterm, Neonatal sepsis, severe jaundice and Neonatal tetanus which is almost similar with our result (11).

The leading contributing factors for neonatal deaths in our series were home delivery, Birth Asphyxia, Preterm delivery, Neonatal Sepsis, Meningitis, Seizure and Tetanus, as are the cases in other findings from other Sub-Saharan African countries $(12,13,14,15)$. Most of these causes of neonatal deaths are largely preventable with simple actions (care). In our study, we observed that $36 \%$ of the mortality occurred within 24 hours of neonatal age. Basic trainings on essential newborn care and proper newborn resuscitation skills immediately after birth proved to reduce mortality among babies born with asphyxia by up to $40 \%(16,17,18)$. Prematurity with its complications was found to be an important contributor of neonatal death in this study. Management of premature babies requires highly specialized equipment, highly trained personnel and adequate financial support. Despite the challenges of meeting these in our environment, some specific and simple measures have been identified, which could be implemented to reduce deaths related to low birth weight and prematurity in low income countries. These simple measures include prophylactic use of steroids during premature labour, antibiotics for premature rupture of membranes, early breastfeeding, treatment of infections, Kangaroo mother care and prevention of hypothermia $(19,20)$. These measures help in reducing the neonatal mortality rate in our setting if effectively implemented and sustained.

Gondar University Hospital is a tertiary hospital which serves as a referral centre to all the health centers and hospitals around the region. Some of the babies could have been transported from rural areas with challenges of hypothermia and contamination before getting to the facility and hence increased mortality with Neonatal Sepsis and Hypothermia.

Interventions directed to skilled birth attendant, antenatal care with vaccinations for tetanus and infection prevention can bring about a significant drop in neonatal mortality in developing nations.
It can be concludedthat prematurity with its complications, Birth Asphyxia and neonatal infections are still contributing to neonatal admissions and deaths in our setting. The overall mortality rate was high. We found that Home delivery, Prematurity, Asphyxia, Neonatal sepsis with Meningitis, Neonatal seizure, Meconium Aspiration, and Hemorrhagic Disease were significant predictors of neonatal death. A significant number of these deaths are avoidable through improved quality of antenatal, intrapartum and postpartum care. Knowing the existing pattern of neonatal mortality plays a key role in determining appropriate measures to be applied to reverse the unacceptable trend of newborn deaths in our setting.

\section{ACKNOWLEDGEMENTS}

No funds were received to conduct this study. We are thankful to all nurses, interns and residents who were involved in data collection. We are also grateful to Gondar University Hospital for giving permission to do this research and participants of the study.

\section{REFERENCES}

1. Choi, Ching. "Neonatal and Perinatal Mortality: Country, Regional and Global Estimates [Book Review]." Journal of Population Research, 2007; 1:136.

2. TD Woldehanna, ET Dejene. Neonatal Mortality in a Teaching Hospital, North west Ethiopia.Cent. Afr J Med, 2005;51(3/4):30-3.

3. Gashaw Andargie, Yemane Berhane, Alemayehu Worku and Yigzaw Kebede. Predictors of Perinatal Mortality in rural population of Northwest Ethiopia: a prospective longitudinal study. BMC Public Health, 2013, 13:168.

4. A sathiya susuman. Child Mortality Rate in Ethiopia. Iranian J Publ Health, 2012;41(3): 9-19.

5. Oliver C. Ezechi and Agatha N. David. Overview of Global Perinatal Mortality. Available at: http://www.intechopen.com/books/perinatalmortality.

6. Dr p prashanth kumar, Gemechis. Infant and Child Mortality in Ethiopia: A Statistical 
Analysis Approach. Ethiop J Educ \& Sc, 2010;5 (2):54.

7. Samuel Muluye, Eshetu Wencheko. Determinants of Infant Mortality in Ethiopia: A study based on 2005 EDHS data. Ethiop.J.Health Dev.2012;26(2):72-77.

8. Eugene Zwane, Sdumo Masango. Factors Influencing Neonatal Mortality: An Analysis using the Swaziland Demographic Health Survey 2007. Journal of Public Health in Africa, 2012; 3:18.

9. Jelka zupan, MD. Perinatal Mortality in Developing Countries. N Engl J Med, 2005;353(19): 2091-2099.

10. Rajaratnam JK, Marcus JR, Flaxman AD, Wang H, Levin-Recto A, Dwyer Let al. Neonatal, Post neonatal, Childhood, and Under-5 Mortality for 187 Countries, 19702010: A Systematic Analysis of Progress towards Millennium Development Goal 4. Lancet, 2010;375(9732):214.

11. Ezechukwu CC, Ugochukwu EF, Egbuonu I, Chukwuka JO. Risk Factors for Neonatal Mortality in a regional tertiary hospital in Nigeria. Nigerian Journal of Clinical Practice, 2004; 7(2):50-52.

12. Owa JA, Osinaike AI. Neonatal Morbidity and Mortality in Nigeria. India J Pediatr, 1998; 65(3):441- 449.

13. Lawoyin TO, Onadeko MO, AsekuuOlarimoye EO. Neonatal Mortality and Perinatal risk factors in rural South-Western Nigeria: a community based prospective study. West Africa J Med, 2010; 29:19-23.

14. Nmbaga BT, Lie RT, Olomi R, Mahande MJ, Kvale G, Dalt-viet AK. Cause-specific Neonatal Mortality in a Neonatal care unit in Northern Tanzania: a registry based cohort study. BMC Pediatrics, 2012;12:116.

15. Carlo WA, McClure EM, Chomba E, Chakraborty H, Hartwell T, Harris H, Lincetto O, Wright LL. Newborn care training for midwives and Neonatal and Perinatal Mortality rate in a developing country. Pediatrics, 2010; 126(5):1064-1071.

16. Perlman JM, Wyllie J, Kattwinkel J, Atkins DL, Chameldes L, Hazinski MF, Morley C, Richmond S, Simon WM, Singhal N, Szyld E, Tamura M, Velaphi S. Neonatal resuscitationInternational Consensus on cardiopulmonary Resuscitation and emergency cardiovascular
Care Science with Treatment recommendation.2013copyright, American Academy of Pediatrics; 2010.

17. Wall S, Lee A, Lawn J. Neonatal Resuscitation in low- resource settings: what, who, and how to overcome challenges to scale up? Int J Gynaecol Obstet,2009; 107:47-64.

18. Darmstadt GL, Bhutta ZA, Cousens S, Adam T, Walker N, de Bernis L. Evidence based, Cost Effective Interventions: How Many Newborn Babies can we save? Lancet, 2005; 365(9463):977-988.

19. Vinod PK. The current state of newborn health in low income countries and the way forward. Semin Fetal Neonatal Med, 2006; 11:7-14.

20. Barros F, Bhutta Z, Batra M, Hansen T, Victoria C, Rubens C, Group IGR. Global Report on preterm birth and still birth (3 of 7): evidence for effectiveness of interventions. BMC Pregnancy and Childbirth, 2012; 10(1):53. 